\title{
Kein «theoretischer Riesenbullshit»
}

\section{Urban Laffer}

Prof. Dr. med., Facharzt für Chirurgie, FMH-Mitglied

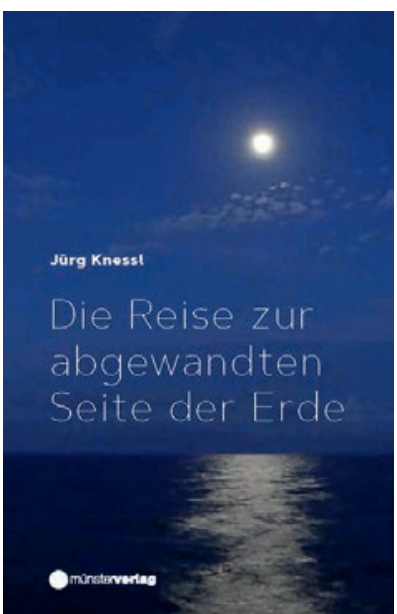

Jürg Knessl

Die Reise zur abgewandten Seite der Erde

Basel: Münster Verlag GmbH; 2018.

296 Seiten. CHF 28

ISBN 978-3-905896-83-1

Viele von uns haben Jürg Knessl als Orthopäde und Standespolitiker kennengelernt. Mit dem vorliegenden Buch überrascht er uns nun auch noch als begabter, polyvalenter und lesenswerter Schriftsteller. Als Autor des Romans - man könnte es auch ein «Sachbuch» nennen - «Die Reise zur abgewandten Seite der Erde» verpackt er, während einer langen Schiffsreise

\section{Dank der tollen und bildreichen Sprache} nehmen wir immer wieder teil an den wunderbaren Naturphänomenen auf hoher See.

von Los Angeles nach Sydney und während des Rückflugs von Australien nach Hause, die Geschichte der Philosophie und ihrer Philosophen, die Probleme von Politik und Ethik und die aktuellen Probleme der Gegenwart und der Zukunft in einen kontroversen Diskurs zwischen Vater und Sohn. Till, der Sohn, 25-jährig, und Leo, der Vater, nutzen 22 Tage und $14500 \mathrm{~km}$ auf dem Wasser für ihre tiefsinnigen Gespräche. Diese leb- haften Diskussionen, die teilweise offensichtlich vom Generationenkonflikt geprägt sind - «alles das, sei mir bitte nicht böse, ist ein theoretischer Riesenbullshit», meint der Sohn zum Beispiel an einer Stelle zu Vaters Meinung -, vermitteln dem Leser einen gut verständlichen, spannenden und mühelos lesbaren Einblick in die Philosophie von der Antike bis zur Gegenwart, in die politischen Probleme der Vergangenheit und der Gegenwart, in die aktuellen Probleme im Bereiche der Natur, des Darwinismus, der digitalen Zukunft, der Religionen, der Ethik und anderer sozialer Grundsätze. So ganz nebenbei, aber ebenfalls auf eindrückliche Art und Weise, gibt uns der Autor auch Einblick in die verschiedenen Stationen der langen Schiffsreise. Dank der tollen und bildreichen Sprache des Autors erleben wir die angesteuerten Aufenthalte in den verschiedenen exotischen Orten wie Hawaii, Honolulu, der Insel Kaua'i, Samoa, Fidschi, Auckland und schliesslich Sydney und nehmen dank der eindrücklichen Beschreibung immer wieder teil an den wunderbaren Naturphänomenen und Naturschönheiten auf hoher See.

Der Journalist Wolfgang Koydl schreibt auf der Rückseite des Buchumschlages: "Eine Kreuzfahrt wird zur eindrucksvollen Reise durch 2000 Jahre Weltgeschichte, Religion und Philosophie. Mit Tiefgang, aber unterhaltsam, voll dunkler Skepsis, aber erhellend. Ein intellektueller Hochgenuss.» Dieser Meinung kann ich mich nur vollumfänglich anschliessen. Jürg Knessl hat mit seinem Buch meine längst veralteten philosophischen Kenntnisse weder aufdringlich noch belehrend aufgefrischt, die Weltgeschichte auf unterhaltsame Art und Weise reflektiert und mit seinen religiösen und ethischen Diskussionen an mehreren Stellen des Buches zum Nachdenken angeregt. Dass dabei der Sohn Till nicht immer gleicher Meinung ist wie der Vater, macht das Lesen unterhaltsam und erfrischend. Die fast 300 Seiten sind zu keinem Zeitpunkt langweilig, und wenn sie langweilig zu werden drohen, werden sie humorvoll und mit Witz mit dem Mittel des Generationenkonfliktes zwischen Vater und Sohn aufgelockert. Eine sehr empfehlenswerte Lektüre nicht nur für Orthopäden und Chirurgen! 